\section{Girl Up}

Laura Bates. London, UK: Simon \& Schuster, 2016. ISBN-13: 978-1-471-14950-4. Price f12.99. Pages: 352 (paperback).

As a sexual health clinical nurse specialist delivering sex and relationship education to a wide variety of young people and professionals, I am always looking for new material to assist with tackling the various complex issues facing young people today. Consequently I was delighted to review this book by the founder of the universally acclaimed project 'Everyday Sexism'.

Girl Up covers a whole range of topics relevant for today's society. It addresses issues that many young women face head- on, challenging stereotypes. Topics such as sex, sexuality, feminism and body image are all included, as are social media and consent.

Laura addresses these areas in a nononsense well-researched and illustrated, straight-talking way. However, I am not convinced that this is an accessible book for young women from all backgrounds. At times, the strong language seems unnecessary and to have been used more for shock than to add to the book's content.

I would say that this book is written for a niche market and may not address many of the groups I work with not because the topics are irrelevant but because of the way they are presented.

I am also not clear what age group this book is aimed at. Personally, I would be starting to discuss these issues with younger teenagers, and I am not convinced that this book is suitable for them.

Some of the information regarding contraception and sexually transmitted infections is not completely accuratefuture editions of the book could be reviewed by a specialist.

The chapters could have flowed better, similar topics could have been grouped rather than scattered throughout the book, and information on where to go for help and support could have been more accessible or highlighted.

Niah, a 16-year-old girl I asked to read the book, criticised the coarse language, though acknowledged that the chatty style may make it seem as though you are in a conversation with a friend. Praising the book's potential to enable girls to not feel powerless in situations where they are oppressed or abused, its factual content, and its eye-opening potential, she nevertheless has reservations. She observes "Girl Up is quite a 'black and white' book in that it focuses on the extremes in society. I'm undecided as to whether or not that's a good or bad thing, but it's good that a book exists to educate those who are growing up in an environment where sexism is a part of daily life, and where parents, friends, teachers are silent about it.

I'm not likely to recommend this book to my friends because they are engaged by eloquence and good reasoning. They prefer writing that doesn't sound 'ranty' and doesn't use unnecessarily vulgar language, writing that helps the reader to relate more closely to the author.

Reviewed by Rachael Duthie

Sexual Health \& Drugs Specialist Trainer (Freelance) and Sexual Health Clinical Nurse Specialist, Cambridgeshire NHS (Part-time), Cambridge, UK; rachaelpmduthie@gmail.com; http://www.rachaelduthie.com

Twitter Follow Rachael Duthie at @rachaelpmduthie

Competing interests None declared.

Provenance and peer review Commissioned; internally peer reviewed.

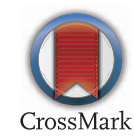

Northern Interbranch Group

An update meeting for the NIBG on Saturday 4th March 2017

at The Hallmark Hotel, Ferriby High Rd, North Ferriby, Hull

HU14 3LG

Provisional Programme includes:

1- Early Medical Abortion and training for the FSRH abortion certificate.

2- Update on menopause guidelines.

3- Contraception and sexual Health for sex workers.

4- Genital dermatoses.

Suitable for FSRH self-certification for $\mathbf{4}$ hours CPD.

Please Contact Farah Chaudhry for an application form at:

farah.chaudhry@nhs.net 